\title{
Computer Aided Techniques Developed for Diagnosis and Treatment Planning in Implantology
}

\author{
Elnaz Moslehifard \\ Department of Prosthodontics, \\ Tabriz University of Medical Sciences, Tabriz, \\ Iran
}

\section{Introduction}

The wide spread application of dental implants with high success rates has made them a common treatment modality in the past two decades. Despite of the predictability of the osseointegration of dental implants, the surgeon has to overcome anatomic limitations as well as restorative demands to achieve precision in planning and surgical positioning of implants. It is essential that the implants are placed properly to ensure a successful operation outcome.

Dental implants are an expected treatment modality for either the restoration of partially and completely edentulous patients or other applications such as anchorage tool in orthodontics (Moslehifard et al, 2011). Successful provision of dental implants to patients lost their teeth and in most occasions their surrounding bone relies on careful gathering of clinical and radiological information achieved with an interdisciplinary communication and detailed planning. Treatment planning is crucial for the success of dental implants.

In osseointegration of dental implants, planning and surgical positioning of implants must be carried out accurately in spite of several inherent limitations. Capabilities of the clinicians, i.e. the surgeon and prosthodontics, play a crucial rule in achieving optimum surgical and prosthetic procedures. The predictability of success is increased when the implants are placed properly. The optimum placement makes it possible to have implants and prosthetic components under establishment of favorable forces. At the early stages of evolution of the implant surgery, clinicians would place implants in regions of maximum bone volume without fully considering where the crown eventually would be placed. Biomechanics, esthetics and maintenance can be compromised if the implant location does not align properly with the crown, ultimately resulting in substandard outcomes, including failure (Worthington et al, 2010).

Several techniques have been developed in years and are currently available in the planning procedure of implant placement during the clinical settings. Palpation of the ridge, use of an osteometer, diagnostic casts and evaluation of the relationship between the jaws, and the use of simple radiographs are the most well established methods beside other advanced methods (Kopp et al, 2003; Fortin et al, 2003). 


\section{Importance of pre-surgical assessment}

The success of any therapeutic treatment depends upon a variety of parameters including careful selection of suitable patients for each treatment, formation of a treatment plan and careful implementation of a gentle treatment procedure. If operator strictly adheres to these principles, any operator-induced damage can be significantly prevented. For instance, the selection of patient and treatment planning is the critical step in the prevention of iatrogenically induced damage during implant treatment. Therefore, a great amount of careful attention should be taken at the pre-surgical era before going through the implementation of the treatment/patient selected.

At the preliminary stages of pre-surgical examinations, the anatomical structures such as vertical height of bone, ridge width, bone quality, vital structures and any bony defects or pathologies are important to learn. It would be also necessary to estimate the number of implants to be placed and their angulations using surgical templates as a useful aid in the orientation of the implant. Bone sites are considered as another issue to address in the presurgical study and should be determined reasonably in quality and quantity. In the other hand, the anatomical limitations for the placement of implants may propagate some damages to the maxillary sinus, mental nerve and inferior alveolar nerve, if not properly introduced in the therapeutic treatment process. Once the anatomical purview of the patient/treatment is established, it is generally recommended to perform the treatment planning in a partially edentulous patient in a manner which does not cause any damage to the adjacent teeth. This may be, for example, obtained when a minimum specified edentulous space retains between the adjacent tooth and fixture. However, there should be a minimum of one millimeter clearance between the apex of the fixture and the superior wall of the inferior alveolar canal. Nevertheless, those cases that are planned with allograft and membranes are less predictable compared to straight forward cases.

During the surgery, vital structures like maxillary sinus, mental nerve and inferior alveolar nerves should not be encroached. The damage occurred in nerves can cause numbness and tingling sensation. The encroachment into maxillary sinus can cause development of oroantral communication. If implants are inserted closely to the maxillary sinus after a poor oral hygiene, it may provide a route to spread infection from the mouth. Once the maxillary dental implant is infected, sinusitis occurs readily due to the spread of inflammation. The perforation of the membranous lining of maxillary sinus occurs commonly during sinus lift operations. The floor of mouth contains branches of submental and sublingual and mylohyoid arteries that may lead to life threatening complications. Damage occurrence to arteries, especially in the floor of the mouth has been reported in the literature (Shenoy et al,. 2006). It can result in most cases in fatal hemorrhage. The branch of the sublingual or facial artery may be situated in immediate contact with the lingual periosteum. This close proximity can explain why even a small perforation could cause severe bleeding (Givol et al,. 2000). Mason et al. (Mason \& Triplett, 1990) reported a case of fetal hemorrhage arising from the dental implant placement in the mandible due to damage to sublingual artery. Injury to the mandibular canal results in paralysis or numbness of the chin and corner of the mouth. Furthermore, sudden loss of tooth vitality within a whole quadrant can occur, since the neurovascular bundle within the mandibular canal also supplies the teeth. The damage to the mandibular canal during the placement of implants (or extraction of third molars), therefore, develops one of the major issues for which legal actions may be taken against dentists. The major cause of this pitfall is submandibular fossa, which is a depression on the 
medial surface of the body of the mandible inferior to the mylohyoid line. Submandibular gland is lodged in this fossa.

Studies by Bavitz et al. (Bavitz et al,. 1994) and Hofchneider et al (Hofchneider et al, 1999) indicated that submental and sublingual arteries may locate closely to the lingual cortical plate, from the floor of the mouth. It should be pointed out that the edentulous mandible is even shorter and, therefore, the perforations occurred are deeper in the floor of the mouth. Most of the reports of the floor of the mouth and sublingual hemorrhage have been iatrogenic in nature. Sharp instruments such as rotating dental disks and burs have slipped off mandibular teeth causing injury to the floor of the mouth and even laceration of the sublingual artery. Niamtu (Niamtu \&Richmond, 2001) reported a case of near fatal airway obstruction after routine implant placement, secondary to sublingual bleeding and hematoma. The submental artery may be located against the usually concave medial body of the mandible in older edentulous patients. The horizontal wall of the submandibular fossa considered in this study has been above the mandibular nerve in all the subjects. Considering the anatomic variations, the risk of perforation is high, especially when the fossa is very deep. When delayed severe bleeding can be taking place, it is prudent to closely follow any patient with a significant penetrating trauma to the floor of the mouth. This includes injuries from iatrogenic dental treatment(s) (Niamtu \&Richmond, 2001). In one study (Parnia et al,. 2010) the depth of submandibular fossa was more than $2 \mathrm{~mm}$ in $80 \%$ of the subjects. This situation raises the risk of perforation of lingual cortical plate, injury to the terminal branches of sublingual artery during implant placement and hemorrhagic accidents, which are critical and life-threatening. Therefore, precise evaluation of morphology and dimensions of submandibular fossa is of utmost importance before implant surgery in the posterior areas of mandible.

The mandibular inter-mental area is assumed to be a safe area for implant insertion and is considered in many other surgical procedures. It is essential to understand the anatomy of the region to avoid occurring injuries to the neurovascular bundles. Provided that the inferior alveolar or mental nerve is damaged during the preparation of an osteotomy, sensory dysfunction may appear due to nerve damage in the foraminal area. All-on-four procedure which has been recently developed, permits a quick placement of 4 dental implants in the interforaminal area of the lower jaw associated with a fixed bridge during only one appointment. The mental foramen is a strategically important landmark during osteotomy procedures. The inferior alveolar nerve may extend beyond the mental foramen as an intraosseous anterior loop. The location of foramen, as well as, the possibility that an anterior loop of the mental nerve may be present mesial to the mental foramen need to be considered before implant surgery to prevent mental nerve injury. The mandibular canal contains the inferior alveolar nerve and blood vessels and is divided into mental and incisive segments between the roots of premolars. The mental canal deviates toward the mental foramen. However, the incisive canal continues below the incisor teeth where it is generally divided into a plexus of nerve branches until its main trunk is lost (Greenstein\& Tarnow, 2000). In this area lingual foramen is also present that is located in the midline, leveled with or superior to the genial tubercles. The foramen has a branch of the incisive artery that anastomosis with the lingual artery (McDonnell et al,. 1994).

In the establishment of a zone of safety (in millimeters) in implant placement, both the available bones coronal and anterior to the foramen are quite important. Any improper implant insertion anterior to the mental canal can cause oedema of the epineurium. This 
may spread to the main mental branch, leading to neurosensory disturbances. Some authors have reported the evidences of discomfort, pain, and disturbance of sensation after implant insertion into the inter-mental area (Abarca et al,. 2006). Rosenquist assumed that implant failure and neurosensory dysfunction were partly due to the large diameter of the mandibular incisive canal. In this report, it was found that incisive bundle causes implant failure, by migrating of soft tissue around the implant, thus preventing osteointegration (Rosenquist, 1996). In addition, sensory disturbances of the mental nerve region may arise after endosseous implants are installed in the mandibular interforaminal region because of damage to anatomical structures in this area (Wismeijer et al,. 1997).

Other landmarks are anterior loop and incisive canal. The possibility of the presence of the anterior loop does not necessarily mean that implants can be safely placed close to the mental foramen. The sensory disturbances of the lower lip have been reported due to the direct trauma to the anterior looping of the mental nerve. Incisive canal is a continuation of the mandibular canal anterior to the mental foramen. The canal contains the incisive bundle that innervates the teeth in the anterior segment. Its precise anatomy and intermedullary content is important during implant insertion. One possible result from traumatizing the neurovascular bundle is sensory disturbance. Kohavi and Bar-Ziv (Kohavi\& Bar-Ziv, 1996) described a case where pain and discomfort resulted from implants placed in the intermental area. CT images revealed that the implants were placed through a large lumen of the incisive canal (Bavitz et al,. 1993). Another factor might also be related to indirect trauma to the incisive canal bundle, causing hematoma in the closed chamber that may produce pressure on the mental nerve. Thus the canal could play an important role in successful osseointegration and prevention of postoperative sensory disturbances.

The lingual foramen is situated in the midline, leveled with or superior to the genial tubercles. A pilot study by Mc Donnell (Mc Donnell et al,. 1994) revealed an incidence of $49 \%$ of the lingual foramen on periapical radiographs of the mandibular incisor region in adult population. The study suggested that the lingual foramen was a consistent finding to the lingual side of the mandible in the midline, being present in over $99 \%$ of the dried specimen examined. The foramen was definitely visible in $81 \%$ and $82 \%$ in Makris (Makris et al, 2010) based on CBCT and Jacobs (Jacobs et al,. 2002) based on CT studies, respectively. The lingual artery has sufficient size to present difficulty in control of hemorrhage intraosseously or in soft tissue. Also in view of its position it could be a factor in implant placement in the midline.

Sufficient knowledge of performing implant surgeries should be available to manage arterial hemorrhage and other medical emergencies. Accurate radiographic imaging is indispensable for the selection of appropriate implant size and placement and is an invaluable guide for surgery.

\section{Imaging objectives}

Over the past decade, there has been a diverse progress in using noninvasive technology to visualize human internal structures in their true form and shape. The discovery of X-ray gave birth to radiology in years. Its outcome developed in dentistry is that the pre-surgical radiographic examinations for the treatment with osseointegrated implant give detailed information on the potential area for implantation. The presence of lesions and anatomical landmarks is known as the confining conditions and structures that may influence the placement of osseous implants. The radiographic examinations should also provide 
evaluation of morphology, angulations of the alveolar ridge, and quantity and quality of the alveolar bone (Tyndall \& Brooks, 2000). The global objective of this phase of treatment is to develop and to implement a treatment plan for the patient that enables restoration of the patient's function and esthetics by the application of accurate and strategic requirements being transformed physically into a three-dimensional diagnostic template. This enables the implant team to identify the specific sites of prospective implant surgery in the imaging examinations. The specific objectives of pre-prosthetic imaging are to (1) identify disease, (2) determine bone quantity, (3) determine bone density, (4) identify critical structures at the proposed implant regions, and (5) determine the optimum position of implant placement relative to occlusal loads (Misch, 2005).

Initially, implants were placed by use of simple periapical and panoramic radiographs (Sarment et al,. 2003). Pre-surgical imaging can provide important information in osseointegrated dental implant treatment. Placement of implants has been performed by use of simple periapical and panoramic radiographs for years (Kopp et al,. 2003). However, surgical templates have attracted much interest in obtaining more precise placement of implant on the surgical site. Because both the final restorative prosthesis, i.e. the biomechanical and aesthetic requirements, and the internal anatomy, i.e. bone volume and position of vital structure, are to be taken into account (Fortin et al,. 2003 ; Misch, 2005).

Proper radiographic assessment is an essential aspect of dental implant planning. Different imaging methods have been used to evaluate bone quantity and anatomic structures in relation to the proposed implant site, ranging from conventional 2-dimentional radiographs (panoramic and periapical radiographs) to more complex 3-dimentional modalities, such as computerized tomography (CT) or cone beam computerized tomography (CBCT).

Some clinicians may solely evaluate the edentulous site on periapical and/or panoramic radiographs. The results of these radiographic evaluations can be enhanced at the time of scanning by the application of a radiographic template with radiopaque markers or materials. Different radiopaque markers, including metal balls and tubes, gutta-percha, and barium sulfate, have been used to delineate the position and/ or the contour of the proposed restoration, but little or no information exist about the restoration contour of the proposed restoration, or it can decrease the quality of the image by increasing the scatter artifact (Zahran \& Fenton, 2010). The main drawback of both techniques for implant treatment is that the images are two-dimensional. Studies have shown that only $17 \%$ of panoramic radiographs reveal true osseous height on dried specimens (Richtert, 1989). In the posterior mandibular region the buccolingual location of the mandibular canal and submandibular fossa are of utmost importance because there is a potential risk of causing damage to the inferior alveolar nerve and submental and sublingual arteries during surgery. The mental foramen is an important landmark where implant placing must be performed in the foraminal region of the mandibular arch. To prevent the mental nerve injury during implant surgery, it is necessary to define the location and also whether an anterior loop of the mental nerve may become mesial to the mental foramen. Sensory dysfunction due to nerve damage in the foraminal area could occur provided that the inferior alveolar or mental nerve is damaged during osteotomy. Since improper placement of implant in the intermental area causes pain and discomfort, reported in several cases, a zone of safety (in millimeter) for implant placement must be determined. However, neither the panoramic nor the periapical films can provide correct information (Parnia et al,. 2010). 


\section{Pre- prosthetic imaging}

\subsection{Intraoral radiography}

\subsubsection{Periapical radiography}

Periapical radiographs are the images of a limited region of mandibular or maxillary alveolus. Periapical radiographs may suffer from distortion and magnification. The long cone paralleling technique eliminates distortion as long as it limits the magnification to less than $10 \%$. The opposing landmark of available bone in implant dentistry is beyond lingual muscle attachments in the mandible or beyond the palatal vault in the maxilla. As such, the image most often must be foreshortened to visualize the opposing cortical plate. As a result, the actual available bone height may be difficult to determine. In terms of the objectives of preprostetic imaging, periapical radiography is (1) a useful high-yield modality for ruling out local bone or dental disease; (2) of limited value in determining quantity because the image is magnified, may be distorted, and does not depict the third dimension of bone width; (3) of limited value in determining bone density or mineralization ( the lateral cortical plates prevent accurate interpretation and cannot differentiate subtle trabecular bone changes); and (4) of value in identifying critical structures but of little use in depicting the spatial relationship between the structures and the proposed implant sit (Misch,2005; Goaze \&White, 1992).

\subsubsection{Occlusal radiography}

Occlusal radiographs have minimal application in implant dentistry. Cross-sectional occlusal radiographs of the mandible give some information about the buccolingual dimension of the mandible, but this information is only accurate in comparison to the inferior aspect of the body, not the width of the alveolar ridge where the implant is to be placed. The use of cross-sectional occlusal radiographs can be helpful when evaluating the position of the implant within the jaw following placement; this applies to both the mandible and maxilla (Mansour \&Dudhia, 2008).

\subsection{Extraoral radiography}

\subsubsection{Cephalometeric radiography}

Lateral cephalometric radiographs provide accurate information about the available bone in the mid-sagittal region of the maxilla and mandible. Because of the long film-focal distances used in cephalometric radiography the resultant image has minimal magnification. The cross-sectional dimensions and morphology of the ridge are shown accurately in the midsagittal plane of the anterior maxilla and mandible.

\subsubsection{Panoramic radiography}

Panoramic radiography is a curved plane tomographic radiographic technique used to depict the body of the mandible, maxilla, and the lower one half of the maxillary sinuses in a single time. This modality is the most useful diagnostic modality properly utilized in implant dentistry. However, for quantitative pre-prosthetic implant imaging, panoramic radiography is not the most diagnosing way (Grondahl K, 1996; Dove\& McDavid, 1993). When using panoramic imaging for diagnosis, one of the most frequent problems in the panoramic radiography is the loss of definition that happens when either the patient is improperly positioned in the machine or the curve of the mandible does not match the focal trough predetermined by the manufacturer (Truhlar et al,. 1993). One early study has 
shown that only $17 \%$ of panoramic radiographs represent true osseous height on dried specimens (Klinge et al,. 1989). Accordingly, due to inexorable changes in the magnification on horizontal dimensions, panoramic image does not match the real dimension. The vertical magnification is approximately $10 \%$ and horizontal magnification is approximately $20 \%$ and varies depending on the anatomical location, the position of the patient and the focus object distance, and the relative location of the rotation center of the X-ray system. Traditional panoramic radiography is a high-yield technique for demonstrating dental and bone disease. However, panoramic radiography (1) does not demonstrate bone quality/mineralization, (2) is quantitatively misleading due to lack of high magnification and third dimension cross-sectional view, and (3) is of some use in demonstrating critical structures but of little use in depicting the spatial relationship between the structures and dimensional quantitation of the implant site. For the evaluation of the recipient sites and the determination of optimum implant dimension, diagnostic templates having $5-\mathrm{mm}$ ball bearing and being worn by the patient during the panoramic $x$-ray examination enable the dentist to determine the amount of magnification in the radiograph (Misch, 2005). The development of computer technology applied to radiology has allowed the manipulation of image such as converting the conventional radiographs into scanned images to display readily on a monitor. The scanned images can enhance interpretation, for resources such as brightness and contrast control, colorization, and inversion effects which may be applied to radiographic images (Sakakura et al,. 2004).

\subsubsection{Computed tomography}

Three-dimensional radiographic imaging was first conceived in the early 20th century and was proved by calculating an infinite number of projections of image of a three-dimensional object. The original purpose of the use of CT scanner was to examine the human cranium (Hounsfield, 1973). Early devices provided $1 \mathrm{~cm}$ thick axial cross-sectional images. Until 1980s technical developments resulted in obtaining 1.5 to $2 \mathrm{~mm}$ thick images. For several years, the technique was used to diagnose the lesions of the head and neck and for the evaluation of the anatomic structures of patients who were to undergo craniofacial surgery (Iplikcioglu et al,. 2002). CT scans have become one of the most frequently used imaging techniques for pre-operative evaluation of the jaws before implant treatment. The first commercially developed program was DentaScan (General Electric,Milwaukee, Wis), which produced "dentistry-friendly" images (Schwarz et al,. 1987).

CT produces axial images of a patient's anatomy. Axial images are produced perpendicular to the long axis of the body. CT images are inherently three-dimensional. The original imaging computer can create secondary images from almost any perspective by reprojecting or reformatting the original three-dimensional voxel data. These images can be used for diagnostic imaging (Kawamata et al,. 2000). A patient's slice data from CT scan images is analyzed via automatic contouring algorithms to provide a representation of the surface of the studied structures (Woolsen et al,. 1986). These structures can be displayed on the screen, compared against normative references for surgical planning, and modified to represent a simulated surgical operation. Implant design and bony augmentation can be simulated on-screen as well (Benjamin, 2002).

Computer tomography (CT) assisted implant planning systems can considerably enhance the quality of implant therapy by improving the transfer from planning to surgery and the ability to convey the treatment plan to the patient. The significance of proper prosthetically 
driven treatment planning was reorganized first with the aim of the optimal crown position used as a guide to implant position. CT is considered a valuable tool towards achieving this goal and enables the use of a three-dimensional image for the diagnosis of osseous features, including its density, volume and architecture, and the identification of vital anatomic structures (such as the maxillary sinus and the mandibular canal) in the radiographic image. Prosthetic and radiographic implant planning can be further enhanced with computer software, using template-guided surgery enabling the clinician to optimize implant position, angle, diameter and length (Horwitz et al,. 2009).

In 1986, Fellingham first demonstrated the use of interactive graphics and 3D modeling for surgical planning, prosthesis, and implant design. 3D images were transmitted to a computer-controlled milling machine for reproduction of the anatomical structure. This technology was used to reproduce atrophic mandibular and maxillary jawbones for full arch subperiosteal implants (Fellingham et al,. 1986). After that, multiplanar reformatted CT had become the most comprehensive and accurate aid for endosseous implant treatment planning. Advancement in diagnostic technology, namely helical or spiral CT and stereolithography, have allowed the development of a CAD-CAM processed surgical guide to be placed directly on the bony site. The surgical guide facilitates the predictable transfer of the analysis of the bony morphology and accurate positioning of the endosseous implant (Cucchiara et al,. 2001).

Limitation of this technique includes the determination of bone quality by use of the imaging computer; hard copy images that only include a limited range of the diagnostic gray scale of the study; and the tilt of the patient's head during the examination, which is critical because all the cross-sectional images are perpendicular to the axial imaging plane. CT examinations are expensive and deliver a relatively high radiation dose to the patient. During dental radiographic procedures, organs most susceptible to the side effects of radiation are the hyoid gland, brain, active bone marrow, lymphatics, and salivary glands. However, although the biologic effects of radiation are known, the risk associated with CT is assumed to be low (Iplikcioglu et al,. 2002). Usually a diagnostic template is necessary to take full advantage of the technique. The diagnostic template enables the dentist to incorporate the three-dimensional treatment plan of the final prosthetic result into the imaging examination; evaluate the patient's anatomy relative to the proposed implant sites; esthetics; and occlusion; and record and transfer these finding to the patient at the time of surgery. CT enables identification of disease, determination of bone quantity, determination of bone quality, identification of critical structures at the proposed regions, and determination of the position and orientation of the dental implants (Misch, 2005).

\subsubsection{Cone beam computed tomography}

Cone beam volumetric tomography was pioneered at the Nihon University School of Dentistry during the 1990s, and the first machines became commercially available in 2000 (Terakado et al,. 2000; Ito et al,. 2001). Since then, numerous machines have been commercialized and much research on the usefulness of the technology in dentistry have been performed. Cone-beam technology is progressing rapidly and scanners are constantly being refined and upgraded. A reasonable number of scanners have already been installed in dental practices and radiology practices, and this number is sure to grow in the future. While CBCT permits three-dimensional visualization of the dental hard tissues in a similar manner to multislice $\mathrm{CT}$, there are some fundamental differences. With the majority of cone- 
beam machines, the patient is seated or standing rather than being supine (Vannier, 2003; Monsour \&Dudhia, 2008). This imaging modality is very promising with regard to preimplant imaging. CBCT generally delivers a lower dose to the patient compared to CT and provides reasonably sharp images with three-dimensional information. While CBVT permits three-dimensional visualization of dental hard tissues in a similar manner to multislice CT (Vannier, 2003), there are some fundamental differences. Image acquisition times vary and are specific to particular models, but typically range between 10 to 70 seconds (Scarfe et al,. 2006; Pinsky, 2006). Acquisition time with a 16-slice CT scanner is shorter than the fastest CBCT scan, and newer 64-slice CT units reduce the scan time even further. This effectively minimizes the risk of patient movement. The theoretical resolution of CBCT is higher than CT (Sato et al,. 2004), but the difference may not be as significant as once through due to the impact of patient movement resulting from the increased scan times. Longer scanning times utilizing an increased number of images permits increased resolution or a decrease in image noise but with a significantly higher radiation dose and an increased risk of patient movement (Scarfe et al,. 2006). As cone-beam technology was built on the platform of complex-motion tomography, the radiation dose is typically lower than a multislice CT scan of the jaws (Terakado et al,. 2000; Hashimoto, 2003).

Recent studies indicate that CBCT images are of sufficient accuracy for use in pre-implant assessments (Pinsky, 2006; Ludlow et al,. 2007). It has been demonstrated that the error in measurements obtained from CBCT scans is less than $0.5 \mathrm{~mm}$ (Marmulla et al,. 2005). Volume-rendered images obtained from $C T$ data have been found to be superior to those from CBVT. The low exposure parameters of CBVT result in poor soft-tissue contrast compared with CT, (Scarfe et al,. 2006; Katsumata et al,. 2006) and the inability to alter the exposure parameters in most machines means that image quality is compromised in larger patients. Furthermore, CBVT suffers from the same beam-hardening artifact that CT does, limiting the usefulness of the exam in patients with metallic restorations, posts or surgical plates (Guerrero et al, 2006).

While it is recognized that multi-slice CT is a higher dose examination way compared to CBVT, some reports indicate that low-dose CT protocols result in significantly less exposure than previously thought, without compromising image quality significantly (Ekestubbe, 1999). A consequence of the lower dose of CBVT is the reduced contrast and subsequent image quality. It is important to note that while the radiation dose from a CBVT scan may be less than that from low-dose CT, the dose is still significantly higher than that from other forms of dental radiographic examinations (Scarfe et al,. 2006).

\subsubsection{Magnetic resonance imaging}

Magnetic resonance imaging (MRI) has become a powerful imaging tool in medicine. This technique was announced first by Lauterbur in 1972.Useful medical images were produced in the early 1980s (Lauterbur, 1973).Using the magnetic properties of the hydrogen atom, MRI units are capable of producing images of the human body. As the technology is dependent upon the presence of hydrogen atoms, MRI is particularly suitable to imaging soft tissues. Using various radiofrequency pulse sequences and relaxation times, images may be produced to better demonstrate anatomy or pathology in the body. Since MRI relies on the use of a strong magnetic field, MRI examinations are contraindicated in patients with metal foreign bodies in the eyes, ferromagnetic intracranial aneurysm clips, cardiac 
pacemakers, cochlear implants and patients in the first trimester of pregnancy. The presence of certain metals such as amalgam and non-precious alloys will result in considerable artifact on the images and often render the examination useless (Hubalkova et al,. 2002; Hubalkova et al,. 2006). Pure titanium implants show no artifact with MRI, but if there are any impurities in the titanium artifact will appear. Other considerations include the significant cost to the patient for MRI examinations and claustrophobia is a real concern as the examinations are generally performed with the patient in a very confining tunnel. MRI is used in implant imaging as a secondary imaging technique when primary imaging techniques fail (Monsour \&Dudhia, 2008).

Most studies using MRI for pre-implant imaging have focused on the ability of MRI units to locate the inferior dental canal (Eggers, 2005). With MRI the inferior dental canal appears as a black void within the high-signal cancellous bone. If the inferior dental canal is surrounded by sclerotic bone, visualization of the canal is more difficult with MRI as the presence of sclerotic bone results in a low bone marrow signal. The contrary is true for CT, as the presence of sclerotic bone in the mandibular body makes the inferior dental canal more obvious. Magnetic resonance imaging has a significant potential for pre-implant imaging due to the lack of ionizing radiation, but acquisition times can be as long as 30 minutes and there is limited bone information available (Monsour \&Dudhia, 2008).

\section{Surgical guides}

In spite of significant advances in devices and techniques, placement of dental implants in correct position still remains a challenge. Diagnostic casts, probing depths and panoramic radiography can lead to unpredictable results as they do not give three-dimensional (3-D) radiographic information required for correct positioning and orientation of implant (Almong et al,. 2001). Moreover, predictable implant supported prosthesis also requires a determination of final prosthesis in treatment planning stage. Thus for a successful implant supported prosthesis, the prosthodontist should plan the implant positioning in accordance with accurate mesiodistal and buccolingual location, angulation with residual bone and correct implant orientation. To achieve these objectives, surgical guide (stent) with radiopaque marker in conjunction with dental CT scan imaging should be used.

The purpose of stent is to purview the definitive restoration and its relationship to adjacent structures, to communicate the restoration planned by the prosthodontist to the surgeon, to reduce osteotomy and to locate healing screws at the time of second stage surgery (Garber, 1995). For a successful implant supported definitive restoration the implant must be placed at a correct and pre-planned position and angulation. The mesiodistal placement of the implant should aid in preservation of papilla and provide an esthetic implant restoration profile (Lazzara, 1993). The implant should be placed at least $1.5 \mathrm{~mm}$ from the adjacent teeth with a minimum $3 \mathrm{~mm}$ interimplant distance. The distance of implant from buccal and lingual cortical plates should be greater than $0.5 \mathrm{~mm}$. In the buccolingual plane the angle between the implant trajectory and residual bone trajectory should be less than 20 degrees to prevent unfavorable bending moment (Horiuchi et al,. 1995; Almong et al,. 1995). In multiple implant situations, non parallel implant placement is the primary cause of non axial loading and subsequent failure (Taylor et al,. 2000). It has been suggested to use stents to achieve the above mentioned objectives. Information present in the literature implies when the implants are placed using stents, the outcome of the positioning is more accurate than those placed without stent (Talwar et al,. 2011). 


\subsection{Diagnostic template}

Evaluation of bone for implant placement may be provided through the use of radiographic or dual-purpose stents. Since the ultimate objective of implant placement is a functional, aesthetic, and durable restoration, the imaging of potential recipient sites should provide accurate information that facilitates precise placement of implants in a correct threedimensional position (Cehreli \& Sahin, 2000). Placement of implants in the anterior maxillary region requires special attention. localized soft tissue and bone contour may affect the emergence profile and the final appearance of the prosthesis. Implants over-angulated toward the labial can lead to aesthetic disharmony. For extremely malaligned implants, an opening for screw access on the facial surface of the prosthesis or its complete removal may be indicated. Implants placed in the inter-proximally areas of a prosthesis may cause aesthetic and hygiene problems, and implants placed too lingually generally result in a bulky prosthesis with an unfavorable lingual contour that may also interfere with speech (Iplikcioglu, 2002).

The goals of presurgical prosthodontics that converts to a radiographic stent include: (i) establishment of vertical dimension of occlusion and adjustment of sufficient interocclusal gap space, (ii) determination of centric occlusion at centric relation position (centric occlusion position is used to mount the casts of patients who are only partially edentulous and have enough remaining teeth), (iii) creation of a harmonious plane of occlusion, (iv) achievement of optimum esthetics, phonetics, and (v) incisal guidance so as not to alter the patient's speech patterns, and (vi) definition of the end result of treatment and its appearance.

Prior to the CT scan, a scan prosthesis that plays several critical roles in obtaining accurate roles in obtaining accurate input data is developed. The scan prosthesis stabilizes the opposing jawbones to prevent jaw movement during the CT scan. Movement is minimized with the helical CT, even slight jaw movement needs to be prevented. Second, occlusion and future tooth set-up can be simulated and represented in 2D and 3D reconstruction. The base of the scan prosthesis should be constructed to represent a radiolucent appearance on the transaxial images. Porous maxillary bone and knife-edge ridges on the mandibular bone must be distinguished from the CT scan prosthesis. Prosthetic teeth are represented as radio-opaque images clearly distinguishable in form and shape. Simulation of the prosthetic tooth position can be accomplished using opaque dental teeth, or coating acrylic teeth with barium sulfate, or using gutta percha markers or a similar radio-opaque material. In addition, the drilling hole must represent the drilling direction for implant insertion (Benjamin, 2002).

There are different surgical templates. Clear vaccuform stents are simple and quick to fabricate but the stents bear too much flexibility in the positioning of implant and are less accurate. Self cure acrylic stents with channels filled with gutta percha provide acceptable accuracy and are easy to fabricate and inexpensive. Self cure acrylic stents with metal sleeves are the most accurate tools in this respect.

Templates are usually fabricated in the laboratory with heat-cured acrylic resin. To indicate screw-access channels, 2-mm-diameter holes should be drilled in the cingulum area of the anterior teeth and the central fossa of the posterior area so that the channels do not interfere with the interproximal papillae or the opposing dentition. After fabrication of the surgical template, it will be drilled by the clinician forming pilot holes or grooves as indicators to implant positions or planned osteotomies, respectively (Zinner et al,. 2004). Figure 1 
illustrates an image of milling machine used for the preparation of the access holes in the surgical template. During the surgery, these stents dictate the implant's position and angle. The stents can combine with CT scan to increase accuracy of the stent. Tomography and CT have been used to provide a three-dimensional picture of the region to be implanted (Ames et al,. 1980; Hollender \&Rockler, 1980). Reformatted computed tomography (CT) has been proven to be an effective technique in planning complex cases in oral implantology (Besimo et al,. 2000). Pre -surgical imaging can provide important information in osseointegrated dental implant treatment. The use of cross-sectional images in the bucco-lingual direction, which can be delivered by computed tomography (CT), allows us to plan a more accurate design of implant placement before surgery (Naitoh et al,. 2000).

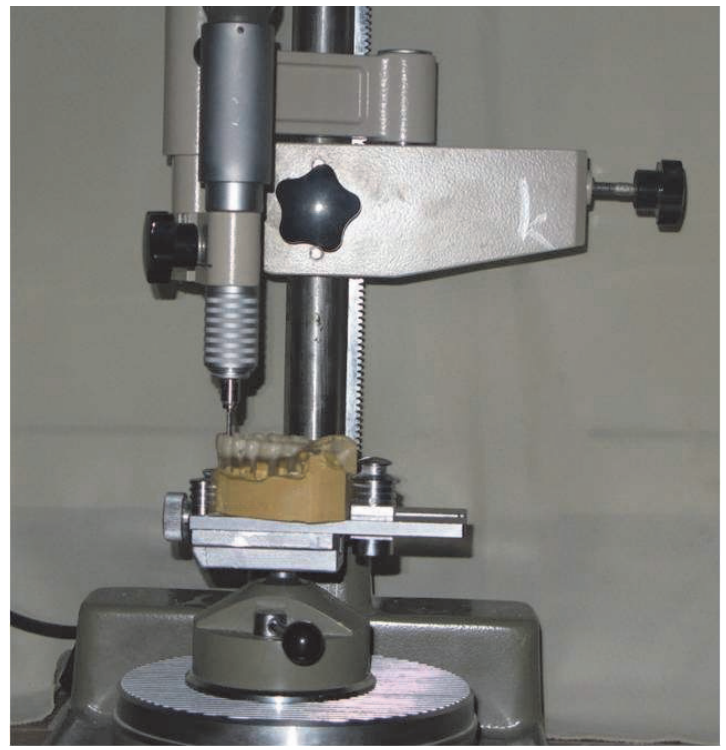

Fig. 1. A scheme of the preparation of implant access holes along the long axis of teeth using milling machine.

This template is the key to the system, since it allows the transfer of the predetermined prosthetic setup to the actual implant planning. The template is an exact replica of the desired prosthetic end result. Incorporation of the scanning template into the computerized tomography (CT) scanning data allows the surgeon to base implant planning on the desired prosthetic outcome. The treatment plan is thus driven by the prosthetic final result, not vice versa (Tardieu \& Philippe, 2001). According to the literature, scannographic template can be made of $15 \mathrm{wt} \%$ of barium sulfate in resin powder, or by means of other radiopaque substances (Wouteres et al,. 2000; Tardieu \& Philippe, 2001). However, a variety of mixtures of barium sulfate ranging between 5 and $35 \mathrm{wt} \%$ have been used. It has been experimentally revealed that the percentage should vary with respect to the surrounding elements (metal crowns or natural teeth) and also as a function of the opacity gradient that one wants to obtain within the same template containing several different radiopaque layers (Tardieu et al,. 2003). In figure 2, radiopaque templates are shown. 


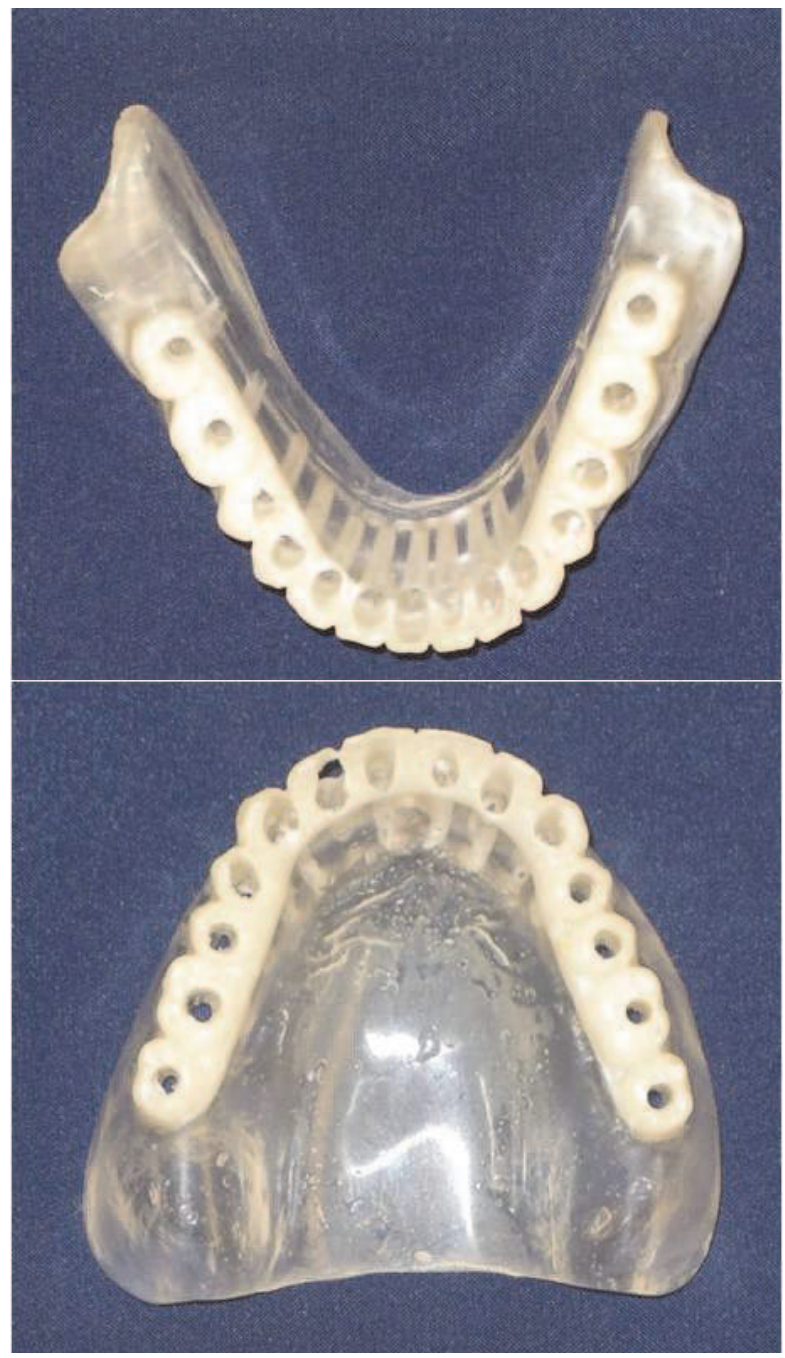

Fig. 2. Radiopaque templates.

In comparison to conventional radiographic stents, radiographic or dual-purpose stents with radiopaque markers offer the advantage of transferring the $\mathrm{CT}$ data onto the same stent for surgery. However, since errors which appear in the conversion of the stent may lead to malalignment of the implants, the angle of the radiopaque markers should facilitate reorientating the surveying table if guide channel preparation must be performed in a different angle.

The incorporation of treatment planning modified by CAD-CAM offers significant advantages, including the evaluation of the 3-D anatomy and the fabrication of anatomic site models and osseous-supported surgical templates. Other advantages include shorter surgery durations, shorter treatment times, minimizing of intraoperative radiographs 
during implant placement, less invasive surgical technique (flapless surgery, with less change of swelling, less pain, and faster initial healing times), prefabricated definitive prosthesis and immediate use of a fixed prosthesis (Saement et al,. 2003; Machrack, 2005). Furthermore, the surgical guides are useful to determine and insert the dental implant in appropriate position and length (Nokar et al,. 2011).

\subsection{Scanning}

The patient must be instructed on how to position the guide in the mouth and how to stabilize the guide by biting on two cotton rolls or on a bite template during CT scan (Fig. 3). The radiographic template can be visualized in both the 2D and 3D reformatted CT images. The concentration of barium sulfate used in creation of the ScannoGuide determines the level of visibility. It is crucial to remember that very low concentrations may result in a lack of visibility of the template in the CT images. And, concentrations of barium which are too high can cause artifacts and minimize proper visualization. It is possible to vary the concentration of barium between the teeth and the base plate of the ScannoGuide, so that both parts can be visualized separately. A hole can be drilled along the longitudinal axis of the tooth. This hole will appear black in the CT images and is clearly visible in 2D crosssectional reconstructions. The following pictures illustrate what can be seen using a proper ScannoGuide in 2D and in 3D. Having the patient bite on cotton rolls has several advantages, it allows arches stabilization during CT scan, it gives a better comfort to the patient who can bite on something solid and it separates jaws avoiding artifacts from the opposite arch. The axial view clearly shows the image of teeth with open hole through. 3D images of the ScannoGuide can be combined with the bone information. The 3D reconstruction of the $\mathrm{CT}$ images of a ScannoGuide can show the teeth set-up for this partially edentulous case.

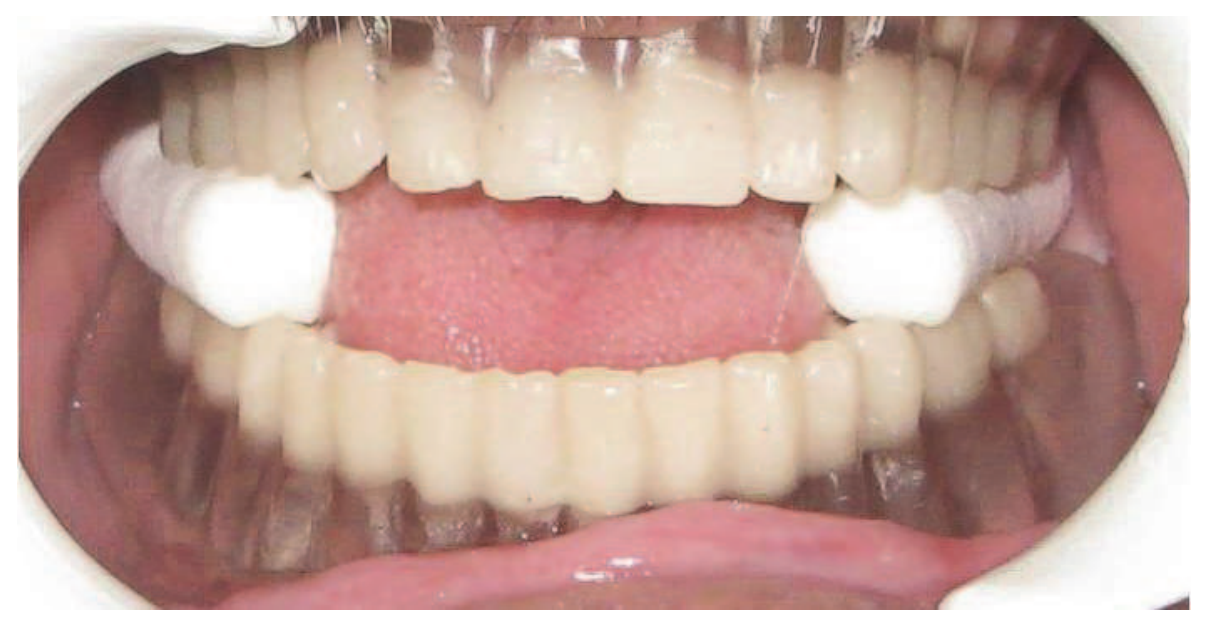

Fig. 3. Stabilizing the templates during CT scan

\subsection{Process of the images and conversion of imaging data}

The CT scan image data must be produced according to a specific scan protocol to obtain the data compatible with the imaging software. The imaging software (Mimics, 
Materialise/Columbia Scientific, Glen Burnie, Md) converts slice image data into 2D and 3D computer models for analysis. The imaging software performs 2D image processing by reformatting the data along planes and/or curves. The simplest reformatting is the construction of images that show slices oriented orthogonally to the original plane of section. These are called planar reconstruction: sagittal if they pass through the midline and are oriented front to rear; coronal if they pass through the midline and are oriented left to right; parasagittal or pericoronal if they are parallel to the sagittal or coronal plane and do not pass through the midline; and paraxial if they are obliquely oriented (Herman \&Liu, 1977) (Fig 4).

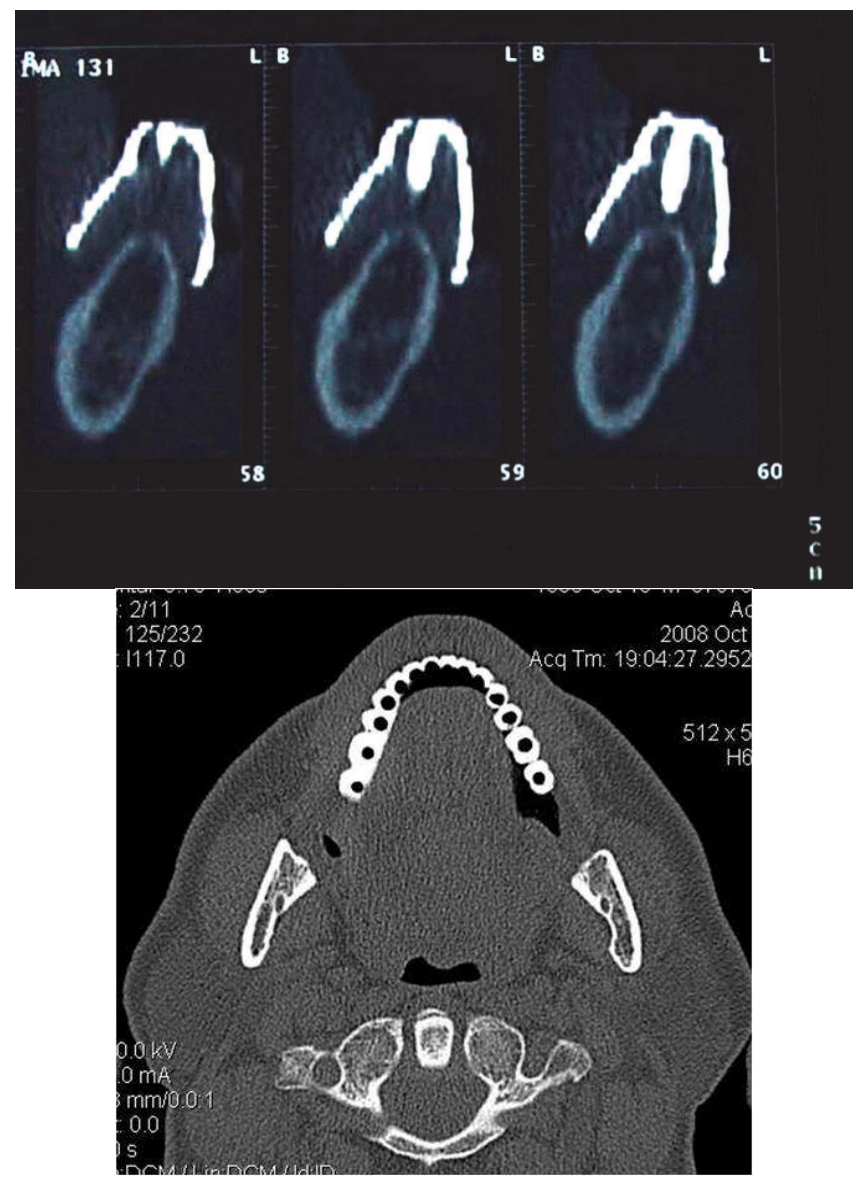

Fig. 4. CT scan images in two views, representing the access holes of radiographic template

In order to make 3D images of the anatomy, a 3D coordinate system must be established. Each slice of data has a location relative to the other slices given by the extent of the table indexed between acquisitions. The distance between slices develops the third dimension rather than the other 2 dimensions including right/left and up/down on each slice (Woolson et al,. 1986). The imaging software can interpret slices taken in a sequence in form 
of a "volume" of data, while the overlap of slices must be inhibited. In order to create a 3D image of bone, for example, the slices are individually processed to extract only the tissue of bone density range. Where necessary, slices are interpolated between the original slices to give a more realistic 3D image. The edges (or contours) of the anatomy of interest, i.e. bone, are stored for the entire set of slices (including the interpolated ones) as a "contour file". The processed contour file is used to create the 3D images (Herman \& Liu, 1977; Liu, 1977). In addition, the imaging software provides the capacity to alter or to edit the contour files themselves. This is useful for editing out obvious metal artifacts, doing disarticulation, or for designing implants. Since the contour file itself is being modified, subsequent 3D images generated from that file will show the results of the editing operation (Woolson et al, 1986). After completion of the scan, the data are sent for data processing. A computer engineer edits the images by removing the scattered and useless parasite images including spinal column, antagonist teeth, and projection of the upper extremities of the mandible for maxillary analysis). The scanning template can be easily identified in axial sections. Different anatomic structures such as maxilla and mandible and the template are separated in different masks. Each of these masks can be toggled on or off to allow separate visualization and interpretation. After calculation of the corresponding 3D models, the patient data were sent back to the surgeon and prosthodontist so that the implant treatment plan could be started (Tardiue et al,. 2003).

\subsection{Treatment planning}

Advances in implant dentistry over the past 40 years facilitate the predictable replacement of missing teeth. It is now common to treat edentulous areas in the mouth partially and fully with implant-supported restorations. In the standard planning for a dental implant case, the doctor procures mounted dental models and designs a surgical guide based on the model. Conventional dental radiographs and CT scans help the practitioner determine where the underlying bone relates to the final prosthesis. But in surgery, a crestal incision with subperiosteal reflection of the gingival, a method that can inadvertently displace the modelbased surgical guide, is in most cases required to determine the anatomy of the alveolar ridge. Implants can only be placed in a flapless manner in cases associated with excess amounts of alveolar bone. Even with a model-based surgical guide, placing the implant in the preplanned position depends on the skill of the operator. The use of model-based guides to position dental implants becomes even more demanding especially in placing multiple implants, as in an edentulous arch with limited bone available (Spector L, 2008).

The incorporation of treatment planning modified by CAD-CAM offers significant advantages, including the evaluation of the 3-D anatomy and the fabrication of anatomic site models and osseous-supported surgical templates. Other advantages include: shorter surgery times, shorter treatment times, minimizing of intraoperative radiographs during implant placement, less invasive surgical technique (flapless surgery, with less change of swelling, less pain, and faster initial healing times), prefabricated definitive prosthesis and immediate use of a fixed prosthesis (Sarment et al,. 2003). Furthermore, the surgical guides are useful to determine and insert the dental implant in appropriate position and length. The software allows the practitioner to view the axial images and also the $3 \mathrm{D}$ image. In this stage the length, diameter and position of the implant body can be determined. Using the method, the flapless surgical technique for oral implant placement may be promoted and the invasiveness of surgical techniques may be reduced. The system under test was 
observed to be reliable for the preoperative assessment of both the number and location of implants and implant size(s) needed, as well as potential anatomic complications. These procedures can be done using specialized software and also can be made using simple software. This method is very useful for fabrication of template in dentistry science field because it can eliminate rigid dependency on commercial companies and it can be used widely in clinical situation.

\subsection{CAD/CAM surgical guide}

CAD/CAM (computed-aided design/computed aided manufacturing) systems have evolved over the last two decades and have been used by dental health professionals for over twenty years. In 1971, Francois Duret introduced CAD/CAM in restorative dentistry and, in 1983; the first dental CAD/CAM restoration was manufactured (Priest, 2005). This system can be used in an intraoperative use for dental restoration and fabrication of surgical guides (Fuster-Torres et al,. 2009). Treatment planning decisions made with computer-aided design (CAD) can be easily transferred to the surgical treatment phase, be performed, in turn, with computer-aided manufacturing (CAM). It has been mentioned that CAD can be conducted through reading and interpreting multiplanar computerized tomography (CT) scans, performing measurements, and evaluating anatomic relationship by placing virtual images on the screen. In the CAM process, stereolithography method can be used for the fabrication of three dimensional surgical templates. The method includes a laser beam travelling above the photosensitive liquid acrylic, allowing the surgical template to be polymerized in the layers according to the design. Then, stainless steel tubes are inserted in the spaces that represent implant location. After insertion the tubes, the surgical template is ready for use. Thus, CAD/CAM surgical templates allow the software based planning to transfer to the surgical field. Template-guided implant surgery requires preoperative steps, starting with the fabrication of a radiographic template, CT acquisition with the template in position, computer-assisted implant planning and ending in fabrication and use of a surgical guide for drilling and implants insertion. Template-guided implant surgery requires preoperative steps, starting with fabrication of a radiographic template, CT acquisition with the template in position, computer assisted implant planning and ending in fabrication and use of a surgical guide for drilling and implant insertion (Horwitz et al,. 2009).

\subsection{Custom-made surgical guide}

CT scans, when properly utilized, will help remove the limitations associated with twodimensional imaging modalities for planning implants, and will empower clinicians with more diagnostic information to make informed decisions for their patients, especially when considering immediate-load protocols. The ability to visualize root, tooth-to-implant and implant-to-implant proximity through $3 \mathrm{D}$ technologies is an important step in the advancement of the science of dental implantology. Incorporating the restorative goal with interactive 3D planning tools for the creation of CT-derived surgical templates allows for the highest degree of accuracy and consistency in transferring the treatment plan to the patient at the time of surgical intervention. High-speed spiral CT image files can now be transferred to personal computers for further analysis and being used as reference, and computer programs are available to provide 3D jaw reconstruction and virtual surgical planning. With the advent of rapid prototyping techniques, virtual computer planning can be linked to the physical production of stereo models and surgical drill guides, which can then ensure an 
accurate transfer of data from the planning phase to the clinical setting. Van Steenberghe et al developed a procedure for immediate implant loading in the maxilla using 3D planning and a custom drill template (Van steenberghe et al, 2002). Their preliminary results indicated that this procedure is effective, precise, and safe (Chow, 2005). Furthermore, horizontal stabilization pins (a minimum of one in partially edentulous cases and up to four in edentulous cases) are virtually placed through the labial denture flange to anchor the surgical template during surgery. After the restorative dentist and surgeon approve the virtual treatment plan, the three-dimensional computer planning files are digitally sent through for fabrication of the stereolithically constructed surgical template (Spector L, 2008).

\subsubsection{Computer simulation and virtual implant planning}

Computer simulation and virtual implant surgery are valuable tools developed for treatment planning. Three dimensional images allow clinicians a direct visualization of the jawbone morphology, bone volume, level of the maxillary sinus floor, and the location and course of the inferior dental nerve. Computer simulation also allows clinicians to place dental implants according to the future prosthetic tooth position. Furthermore, clinicians can study their cases alternatively and modify the virtual surgical implant placement until they are fully satisfied with the plan. Such surgical rehearsal is a kind of mental navigation system allowing further improvement of clinical performance. Computer simulation and virtual planning are, however, associated with some disadvantages including radiation hazards, and greater requirements for resources and time.

Originally, surgical drill guides were used only for the preparation of implant osteotomy. In 2003, Tardieu and Vrielinck introduced the SAFE System for dental implant placement using a single surgical guide for both the drilling and implant placement. When it is possible to control the position, angulation, and the depth needed for drilling and implant placement, this kind of template-navigated procedure can be safe and accurate ( Tardieu \& Vrielinck, 2003). Although the precision of the surgical drill guides is high, the accuracy of actual implant placement can be affected by the following factors: (1) correct positioning of the guide; (2) fitting the guide to the underlying structures (bone, mucosa, or tooth); (3) stabilization mechanisms (bony irregularities, pins, or screws); and (4) discrepancies between the diameter of the implant drill and the corresponding metal drill sleeve (Chow, 2005).

SurgiCase software allows for the regeneration of 3-dimensional images of the jaw anatomy, which can simulate the insertion of the fixtures. Even bone density in the area of the future implant location can be taken into account. This system contains cylindrical representations of oral implants, and their lengths and diameters can be modified according to the available product sizes of the implant manufacturer so as to obtain the best use of the available bone, and when possible, the contact with the cortical parts of the jaw bone (Sarment et al,. 2003). The magnitude of bone density allows developing a bone map, where it is possible to identify the sites that could assure the fixtures' major primary stability and offer better resistance to the biting forces (Vrielinck et al,. 2003).

The effectiveness of CAD/CAM surgical guides has been studied. For instance, Van Steenberghe et al (Van Steenberghe et al,. 2003) examined the accuracy of a CAD/CAM surgical guide in cadavers or Vrielinck et al (Vrielinck et al,. 2003) performed a similar study in human subjects. Vercruyssen (Vercruyssen \& Quirynen, 2010) has discussed possible errors of CAD/CAM surgical guides, which may occur at any of the following stages: CTscan data collection, positioning of the radiographic guide, segmentation of bone, teeth, 
and/or tissue from the complete image, stereolithographic or CAD/CAM modeling, fixation of the surgical guide to the jaw bone, and use of precision sleeves. This type of precise surgical guide has also presented some challenges to clinicians. Yong and Moy studied early complications using CAD/CAM-guided implant placement with the NobelGuide system (Nobel Biocare AB, Goteborg, Sweden) claiming that the most common early surgical complication includes incomplete seating of the prosthesis due to bony interferences (Yong \&Moy, 2008).

\section{Stereolithography}

Once CT scan data are segmented, the software interpolates the data on all 3 planes to form a smooth 3D model. A computer file of this model can be alternatively transferred to stereolithography equipment where a physical model of the patient's bone structure is created. The finalized treatment plan is thus used for fabrication of a surgical template using this technique.

The stereolithography process is a rapid prototyping method that produces physical models by selectively solidifying an ultraviolet sensitive liquid resin using a laser beam. It represents a relatively new technology in the diagnostic area. The status of this new methodology in clinical and surgical medicine is still at the prototype stage. It can be used for surgical simulation to assure predictable results and to diminish operation time (Choy JY, 2002). In oral implantology, this technology develops a precise evaluation of anatomic points such as the size of the maxillary sinus in the upper jaw and the location of the alveolar nerve in the lower jaw. It also provides information about size, direction, and bone location for accurate positioning of implants. In one study, the possible benefits in planning implant surgery using stereolithographic models and surgical guides relating to clinical guidance methodology have been indicated in detail (Sammartino G et al,. 2004).

From a detailed technical point of view, as point out earlier, stereolithography is a computer-driven process that creates precise models using laser and epoxy resin. A computer controlled HeCd laser generates an ultraviolet beam, which travels across the surface of a vat of photocurable liquid polymer. The laser draws each cross section of the anatomy one layer at a time. The photovoltaic energy from the laser polymerizes the epoxy immediately. The cured cross-sectional layer is lowered into the vat of resin and the next layer is processed. Successive layers of the anatomy are built in $0.15 \mathrm{~mm}$ increments until the model is completed (Herman GT\& Liu HK, 1977).

Using this technique, surgical procedure would be simplified, reliable, and easily reproducible. Wound size and bone surface exposure would be minimal and no soft tissue trauma would be derived by use of burrs during bone drilling. Furthermore, during the operative procedure, there will no major problems of bleeding or nerve lesion. The postoperative time would be without complications.

This technique offers many advantages which include: correct management of the tissues with minimal trauma and a superior planned treatment. In cases of severe atrophy, this methodology allows fixture measurements by the indication of exact surgical limitations, and prevents complications related to poor stability of a denture. This technologic improvement can simplify oral management in implant dentistry and avoid complications related to the surgery (Sammartino G et al,. 2004).

The accuracy of anatomical models generated by this method depends on the quality of the CT scanners and the thresholding method (the computer process that determines what is 
soft tissue), but studies have shown a dimensional stability in general in the range of $0.6 \mathrm{~mm}$ (Choi et al,. 2002). The accuracy of steriolithographically made surgical guides have been studied by different groups. Sarment (Sarment et al,. 2003) used SIMplant software for fabricating template. A significant statistical improvement was found in all measurements when stereolithographic surgical guide was used compared to conventional guides. The average distance between the planned implant and the actual osteotomy was $1.5 \pm 0.7 \mathrm{~mm}$ in conventional group and $0.9 \pm 0.5$ in stereolithographic group. Measurement of the angle formed in conventional group was $8 \pm 4.5$ degrees with an accuracy of $4.5 \pm 2$ degrees in the stereolithographic group. In the other in-vitro study reported by Van steenbergehe and coworkers (Van Steenberghe et al,. 2002), LITORIM software was used for the fabrication of the guide and the match between planned implant and actual implants in the maxilla was on average within $0.8 \pm 0.3 \mathrm{~mm}$ and the match between planned and actual implant axis was on average within 1.8 \pm 1 degrees. Naitoh and colleagues (Naitoh et al,. 2000) suggested that angulation diverges by 5 degrees on average when utilizing a template based on the CT images. Application of stereolithographic surgical guides presented by Giacomo (Giacomo et al,. 2005) gave rise the match between the planned and the placed implant axis within $7.25 \pm 2.67$ degrees. The differences in distance between the planned and placed position at the implant shoulder were $1.45 \pm 1.42 \mathrm{~mm}$. Besimo and associates (Besimo et al,. 2000) utilized a modified scannographic template for surgical guidance. Placement was evaluated by measurement on the casts of more than 70 clinical cases. They found $1.5 \mathrm{~mm}$ differences at entrance point when used control guide and $0.9 \mathrm{~mm}$ when the stereolithographic surgical guide was used. Van sttenberghe (Van Steenberghe et al,.2002) evaluated placement of $45 \mathrm{~mm}$ long zygoma implants on human cadavers. They reported less than 3 degrees of deviation. Fortin (Fortin et al,. 2003) found that transfer error was less than $0.2 \mathrm{~mm}$ and 1.1 degrees.

Tardieu (Tardieu et al,. 2003) presented a case of implant placement using a drill guide created by stereolithography. They suggested that the scannographic template could be designed for proper transfer into a temporary fixed prosthesis which can be used in immediate loading. Mesiodistal accuracy influences implants from esthetic point of view especially in anterior region because the proper embrasures and golden proportional are not established yet. Length difference may also cause complication. A maximum length of $2 \mathrm{~mm}$ above the mandibular canal is generally recommended. If the length exceeds this limitation, it may cause parasthesia and pain leading finally to the removal of implant. Otherwise, if the length is very short, crown to implant ratio may be improper and biomechanical factors compromise the implant integrity. The accuracy of angle causes the forces directed towards the implant long axis.

The main drawback of the surgical template can be seen in the possible movement of the template during surgery and reproducibility of the splint position between the CT exam and surgical procedure. The template is supported on the remaining dentition or stabilized by a specific form of either the hard palate or the mandible. Sicilia (Sicilia et al,. 2000) reached a considerably higher precision using a fixed surgical template in the placement of implants in patients with edentulous maxilla. In a large edentulous area or completely edentulous jaw, the stereolithographic guide is advantageous since it is osseous-supported. The degree of the difference between the proposed and actual implant direction may be influenced by various factors, such as the construction accuracy of the template, the surgical accuracy using these templates, the accuracy of the study model, the accuracy of the stereolithographic machines and the measurement accuracy. The CT scan involves a higher dose/higher cost method. But the CT scan is less time consuming when multiple implants 
are required, and it allows imaging of the entire jaw, making it possible to use software for virtual implant placement (Nokar et al,. 2012). As long as radiographic imaging has been enhanced by the development of various techniques, multi-slice and spiral CT are being replaced by cone beam CT systems (CBCT) for oral and maxillofacial imaging, enabling a significant reduction dose (Loubele et al,. 2008).

\section{Simplified CAD/CAM technique}

This method has been recently developed to generate surgical guide by a much simpler method based on CAD/CAM. For making CAD/ CAM template, anatomic guide was digitized by ATOSII camera (optical measuring technique). The ATOS system was used to digitize the objects and process the data into an STL data set. Some reference points were applied onto the model. By using the photogrammetry camera and its supplied software, coordinates of the points were measured with high accuracy. Three reference markers were applied to each part added. At this stage, a second series of images were taken and the visible reference point coordinates were measured on these images. Using the points on the model, obtained with two sets of measurements, the second set of the points was transformed into the coordinate system that was previously defined after the first measurement. In the next step, all the measurement points were changed to IGES format with Rapid form software and consequently the IGES format was changed to SLD format using Solid work software. This model was assembled on the jaw model. The implant access holes were evaluated and the implant path and length in each tooth were determined. The length of implants was considered $2 \mathrm{~mm}$ above the mandibular canal and the diameter of implant holes was increased up to $4 \mathrm{~mm}$ (Fig 5).

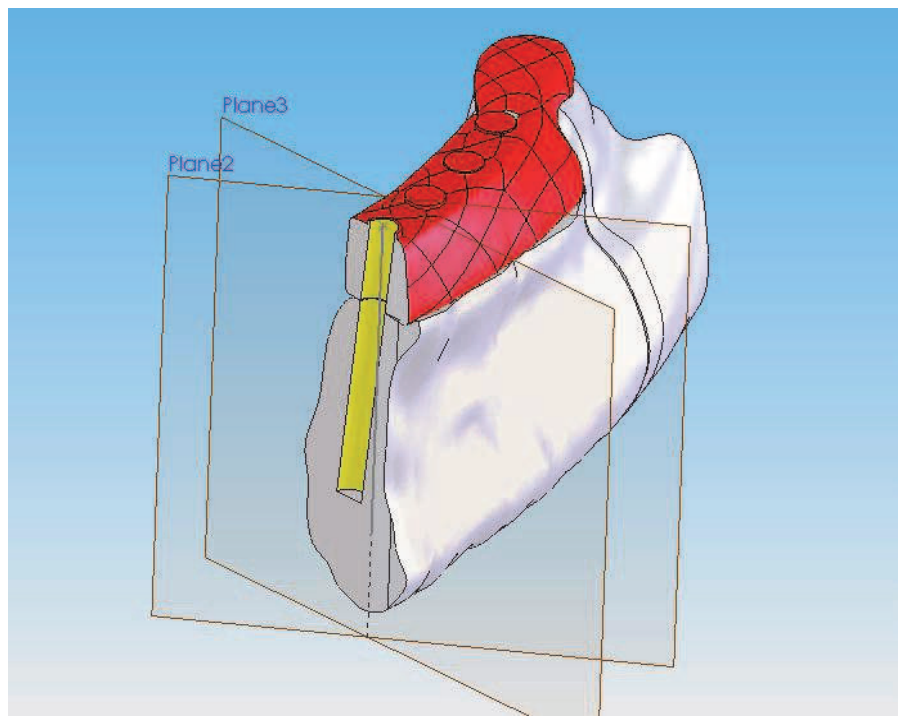

Fig. 5. Drilling direction and implant length determined in Solid work software.

This model, named gold standard model, was filed and applied for evaluating the results. After designing the implant path and length, the CAD-CAM surgical template was 
fabricated using stereolithographic rapid prototyping machine. Then, the stainless steel sleeves were fabricated to be used as drills of implants in two different sizes. The sleeves were, then, inserted in the CAD-CAM template. The sleeves kept the planned implants length and diameter as designed. In the first group, concerning the anatomical surgical template, implant path was modified via measuring CT scan file. For the second group, there was stereolithographic template with incremental guiding tube diameters, fabricated by CAD-CAM techniques (Fig 6).

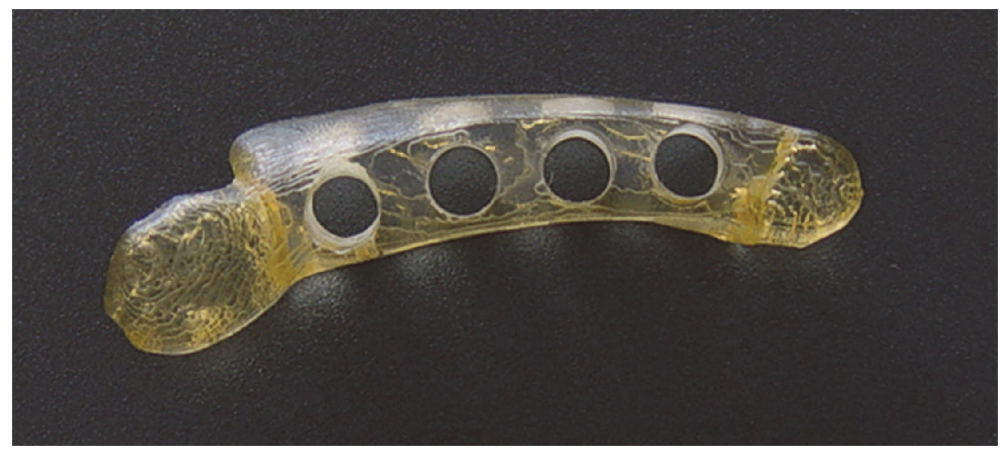

Fig. 6. Fabrication of the guide by stereolithography machine.

\section{Conclusion}

In this chapter an overview to different techniques of pre-surgical diagnosis and treatment planning with emphasis on computer assisted methods was given. At first the importance and all effective parameters in implantology were discussed. In the second section different imaging modalities including intra- oral and extra- oral were reviewed. The next parts described more recent pre-surgical diagnostic procedure which reveals that computer assisted methods enhance the capability of prosthodontists to diagnose and choose a convenient and easy to apply methods for implant placement.

\section{Acknowledgment}

The Author would like to acknowledge Dr Farzad Nasirpouri for careful review and edition of the text.

\section{References}

Almog DM, Onufrak JM, Hebel K, Meinter SW. (1995). Comparison between planned prosthetic trajectory and residual bone trajectory using surgical guides and tomography - a pilot study. J Oral Implantol 21:275-280

Almog DM, Torrado E, Meitner SW .(2001). Fabrication of imaging and surgical guides for dental implants. J Prosthet Dent, Vol (85), pp.504-508

Abarca M, van Steenberghe D, Malevez C, De Ridder J, Jacobs R. (2006). Neurosensory disturbances after immediate loading of implants in the anterior mandible: an initial questionnaire approach followed by a psychophysical assessment. Clin Oral Investig, Vol(10),No.4,pp.77 
Ames JR, Johnson RP, Steven EA. (1980). Computerized tomography in oral and maxillofacial surgery, J Oral Surgery, Vol (38), pp.145-9

Bavitz JB, Harn SD, Hansen CA, Lang M. (1993). An anatomical study of mental neurovascular bundle-implant relationships. Int J Oral Maxillofac Implants, Vol (8), No.5, pp.563-7

Bavitz JB, Harn SD, Homze EJ. (1994). Arterial supply to the floor of the mouth and lingual gingivae. Oral Surg Oral Med Oral Pathol, Vol (77), pp.232-5

Benjamin L. (2002).The evolution of multiplanar diagnostic imaging: predictable transfe of preoperative analysis to the surgical site. J Oral Implantol, Vol (28), pp.135-143

Besimo CE, Lambrecht JT, Guindy JS. (2000). Accuracy of implant treatment planning utilizing template-guided reformatted computed tomography. Dentomaxillofacial Radiology, Vol (29), pp.46-51

Cehreli MC, Sahin S. (2000).Fabrication of a dual purpose surgical template for correct labiopalatal positioning of dental implants. INT J oral Maxillofac Implants, Vol (152), pp. 278-282

Chow JK. (2005).Computer-guided implantology:an overview with a case presentation. Hong Kong Dental Journal, Vol (2), pp.7-11

Choy JY, Choy JH, Kim NK, Kim Y, Lee JK, Kim MK, Lee JH, et al. (2002). Analysis of errors in medical rapid prototyping models. Int J Oral Maxillofac Surg, Vol (31), pp.23-32

Cucchiara R, Franchini F, Lamma A. (2001). Enhancing implant surgery planning via computerized image processing. Int j comput dent, Vol (4), pp.9-24

Dove SB, McDavid WD. (1993).Digital panoramic and extraoral imaging. Dent Clin North Am, Vol (37), No.4, pp.541-51

Eggers G, Rieker M, Fiebach J, Kress B, Dickhaus H, Hassfeld S. (2005).Geometric accuracy of magnetic resonance imaging of the mandibular nerve. Dentomaxillofac Radiol, Vol (34), pp.285-291

Ekestubbe A. (1999). Conventional spiral and low-dose computed mandibular tomography for dental implant planning. Swed Dent J Suppl, Vol (138), pp.1-82

Fellingham LL, Vogel J, Lau C, et al. Interactive graphics and 3D modeling for surgical planning and prosthetics and implant design. Presented at: National computer graphic association conference and exposition. Anaheim, CA, USA, May 11-15, 1986.

Fortin T, Bosson J, Coudert JL, Isidori M. (2003). Reliability of preoperative planning of an image guided system for oral implant placement based on 3D images: An In vivo study. INT J Oral Maxillofac Implants, Vol (18), pp.886-893

Fortin T, champleboux G, Lormee J, coudert J. (2000). Precise dental implant placement using surgical guides in conjuction with medical imaging techniques. Journal of Oral Implatology, Vol (264), pp.300-303

Fuster-Torres MA, Albalat-Estela S, Alcañiz-Raya M, Peñarrocha-Diago M. (2009).CAD / CAM dental systems in implant dentistry: update.Med Oral Patol Oral Cir Bucal, Vol (14), No.3, pp.E141-5

Garber DA. (1995). The esthetic dental implant: letting restoration be the guide. J Am Dent Assoc, Vol (126), pp.319-325

Giacomo DG, Cury P, Araujo N, Sendyk W, Sendyk C. (2005). Clinical application of stereolithographic surgical guides for implant placement: preliminary Results. J Periodontol, Vol (76), pp.503-507 
Givol N, Chaushu G, Halamish-Shani T, Taicher S. (2000). Emergency tracheostomy following life-threatening hemorrhage in the floor of the mouth during immediate implant placement in the mandibular canine region. J Periodontol, Vol (71), pp.1893-1895

Goaz PW, White SC. (1992).Oral radiology:principles and interpretation, Mosby, ST Louis

Grandahl K, Ekestubbe A, Grondahl HG. (1996).Technical consideration for intraoral radiography in postoperative wxamination, Nobel Biocare Global Forum. Vol (10), pp. 10-11

Greenstein G, Tarnow D. (2006).The mental foramen and nerve: clinical and anatomical factors related to dental implant placement: a literature review. J Periodontol, Vol(77), No,12, pp. 1933-43

Guerrero ME, Jacobs R, Loubele M, Schutyser F, Suetens P, van Steenberghe D. (2006). Stateof-the-art on cone beam CT imaging for preoperative planning of implant placement. Clin Oral Investig, Vol (10), pp.1-7

Hashimoto K, Arai Y, Iwai K, Araki M, Kawashima S, Terakado M. (2003). A comparison of a new limited cone beam computed tomography machine for dental use with a multidetector row helical CT machine. Oral Surg Oral Med Oral Pathol Oral Radiol Endod, Vol (95), pp.371-377

Herman GT,Liu HK. (1977).Display of three-dimensional information in computed tomography. Jconput assist tomogr, Vol (1), pp.155-160

Hofschneider U, Tepper G, GahleitnerA, Ulm C. (1999). Assessment of the blood supply to the mental region for reduction of bleeding complications during implant surgery in the interforaminal region. International Journal of Oral and Maxillofacial Implants, Vol (14), pp.379-383

Hollender L, Rockler B. (1980). Radiographic evaluation of osseointegrated implants of the jaws. Dento-maxillofacial Radiol, Vol (9), pp.91-5

Horiuchi M, Ichikawa T, Kanitani HWigianto R, Kawamoto N, Matsumoto N. (1995). Pilothole preparation for proper implant positioning and the enhancement of bone formation. J Oral Implantol , Vol (21), No.4, pp.318-324

Horwitz J, Zuabi O, Machtei EE. (2009).Accuracy of a computerized tomography- guided template-assisted implant placement system;an in vitro dtudy. Clin Oral Impl Res, Vol (20), pp.1156-1162

Hounsfield GN. (1995). Computerized transverse axial scanning (tomography): Part I. Description of system.Br J Radiol, Vol (68), No.815, pp.166-72

Hubálková H, Hora K, Seidl Z, Krásenský J. (2002). Dental materials and magnetic resonance imaging.Eur J Prosthodont Restor Dent, Vol (10), No.3, pp.125-30

Hubálková H, La Serna P, Linetskiy I, Dostálová T. (2006). Dental alloys and magnetic resonance imaging.Int Dent J, Vol (56), No.3, pp.135-41

Iplikcioglu H, Akca K, Cehreli MC. (2002). The use of computerized tomography for diagnosis and treatment planning in implant dentistry. Journal of Oral Implantology, Vol (28), pp.29-35

Jacobs R, Mraiwa N, vanSteenberghe D, Gijbels F, Quirynen M. (2002). Appearance, location, course, and morphology of the mandibular incisive canal: an assessment on spiral CT scan. Dentomaxillofac Radiol, Vol (31), No.5, pp.322-7 
Katsumata A, Hirukawa A, Noujeim M, Okumura S, Naitoh M, Fujishita M, Ariji E, Langlais RP. (2006). Image artefact in dental cone-beam CT. Oral Surg Oral Med Oral Pathol Oral Radiol Endod, Vol (101), No. 5, pp.652-657

Kawamata A, Ariji Y, Langlais RP. (2000).Three-dimensional computed tomography imaging in dentistry. Dent Clin North Am, Vol (44), No.2, pp.395-410.

Kawamata A,Ariji Y,Langlais RP. (2000).Three-dimentional computed tomography imaging in dentistry.Dental Clinic of North America, Vol (44), pp.395-410

Klinge B, Petersson A, Maly P. (1989). Location of the mandibular canal: comparison of macroscopic findings, conventional radiography, and computed tomography. Int J Oral Maxillofac Implants, Vol (4), No.4, pp.327-332

Kohavi D, Bar-ziv J. (1996). Atypical incisive nerve: clinical report. Implant Dent, Vol (5), No.4, pp.281-283

Kopp KC, Koslow AH, Abdo OS. (2003). Predictable implant place ment with diagnostic surgical template and advanced radiographic imaging. J Prosthet Dent 2003, Vol (89), No.6, pp. 611-

Lauterbur PC. (1973). Imaging formation by induced local interactions: example employing nuclear magnetic resonanc. Nature, Vol (242), pp. 190

Lazzara RJ. (1993). Effect of implant position on implant restoration design. J Esthet Dent , Vol (5), pp.265-269

Liu HK. (1977).Two and three-dimensional boundary detection.Comput graph image proc, Vol ( 6), pp.123-134

Loubele M, Bogaerts R,Van Dijck E, Pauwels R, Vanheusden S, Suetens P, Marchal G, et al. (2009).Comparison between effective radiation dose of CBCT and MSCT scanners for dentomaxillofacial applications. European Journal of Radiology, Vol (71), pp.461-8

Ludlow JB, Laster WS, See M, Bailey LJ, Hershey HG. (2007). Accuracy of measurements of mandibular anatomy in cone beam computed tomography images. Oral Surg Oral Med Oral Pathol Oral Radiol Endod, Vol (103), pp.534-542

Makris N, Stamatakis H, Syriopoulos K, Tsiklakis K, van der Stelt PF. (2010). Evaluation of the visibility and the course of the mandibular incisive canal and the lingual foramen using cone-beam computed tomography. Clin Oral Implants Res, Vol (21), No.7, pp.766-71

Marchack CB. (2005).An immediately loaded CAD/ CAM-guided definitive prosthesis: A clinical report. J Prosthet Dent, Vol (93), pp. 8-12

Marmulla R, Wortche R, Muhling J, Hassfeld S. (2005). Geometric accuracy of the NewTom 9000 Cone Beam CT. Dentomaxillofac Radiol, Vol (34), pp.28-31

Mason M.E, Triplett R.G., Alfonso W.F. (1990). Life-threatening hemorrhage from placement of a dental implant. Journal of Oral and Maxillofacial Surgery, Vol (48), pp.201-204

McDonnell D, Reza Nouri M, Todd ME. (1994).The mandibular lingual foramen: a consistent arterial foramen in the middle of the mandible. J Anat, Vol (184), No.2, pp.363-9

Misch CE. (2005). Dental implant prosthetics, Elsevier, China

Monsour PA, Dudhia R. (2008). Implant radiography and radiology. Aust Dent J Suppl, Vol (53), pp.11-25 
Moslehifard E, Nikzad S, Geramipanah F, Mahboub F. (2011). Full mouth rehabilitation of a patient with severely worn dentition and uneven occlusal plane: A Clinical Case Report. Journal of Prosthodontics. Accepted for publication

Naitoh M, Ariyi E, Okumura S, Ohsaki C, Kurita k, Ishigami T. (2000). Can implants be correctly angulated based on surgical templates used for osseointegrated dental implants, Clin Oral Impl Res, Vol (11), pp.409-414

Niamtu J, Richmond. (2001). Near Fatal airway obstruction after routine implant placement. Oral Surg Oral Med Oral Path Oral Radiol Endod, Vol (92), pp.597-600

Nokar S, Moslehifard E, Tootiaii B, Bayanzadeh M, Nasirpouri F.,Nokar A. (2011). Accuracy of implant placement using a CAD/CAM surgical guide: an in vitro study. Int J Oral Maxillofac Implants., Vol (26), PP.520-526

Parnia F, Moslehifard E, Mahboub F, Hafezeqoran A, Gavgani FE. (2010). Tomographic volume evaluation of submandibular fossa in patients requiring dental implants. Oral Surg Oral Med Oral Pathol Oral Radiol Endod, Vol (109), No.1, pp.e32-6

Pinsky HM, Dyda S, Pinsky RW, Misch KA, Sarment DP. (2006). Accuracy of threedimensional measurements using cone-beam CT. Dentomaxillofac Radiol, Vol (35), pp.410-416

Priest G. (2005). Virtual-designed and computer-milled implant abutments. Oral Maxillofac Surg, Vol (63), No.9, pp.22-32

Richtert EJ. (1989). Basic biomechanical of dental implants in prosthetic dentistry.J Prosthet Dent, Vol (61), pp.602-609

Rosenquist B. (1996). Is there an anterior loop of the inferior alveolar nerve?. Int J Periodontics Restorative Dent, Vol (16), No.1, pp.40-5

Sakakura CE, Monteiro LC, Scaf G. (2004).Diagnostic agreement of conventional and inverted scanned panoramic radiographs in the detection of the mandibular canal and the mental foramen. Journal of Implantology, Vol (30), pp.2-6

Sammartino G, Della Valle A, Marenzi G, Gerbino S, Martorelli M, di Lauro AE, di Lauro F. (2004). Stereolithography in oral implantology: a comparison of surgical guides.Implant Dent, Vol (13), No.2, pp.133-9

Sarment DP, Al-shammari K, Kazor C. (2003). Stereolithographic surgical templates for placement of Dental Implants in complex cases. Int J Periodontics Restorative Dent, Vol (23), pp.287-295

Sato S, Arai Y, Shinoda K, Ito K. (2004). Clinical application of a new cone-beam computerized tomography system to assess multiple two-dimensional images for the preoperative treatment planning of maxillary implants: case reports. Quintessence Int, Vol (35), pp.525-528

Scarfe WC, Farman AG, Sukovic P. (2006). Clinical applications of conebeam computed tomography in dental practice. J Can Dent Assoc, Vol (72), pp.75-80

Schwarz MS, Rothman SL, Rhodes ML, Chafetz N. (1987).Computed tomography: Part II. Preoperative assessment of the maxilla for endosseous implant surgery. Int J Oral Maxillofac Implants, Vol (2), No.3, pp.143-8

Shenoy VK, Bhat SG, Rodrigues SJ. (2006).Iatrogenic complication of implant surgery. Journal of Indian Prosthodontic Society, Vol (6), 18, MYK19

Sicilia A, Enrile F, Buitrago P, Zubizarreta J. (2000). Evaluation of the precision obtained with a fixed surgical template in the placement of implants for rehabilitation of the completely edentulous Maxilla. INT J Oral Maxillofac Implants, Vol (15), pp.272-277 
Spector L. (2008). Computer-Aided Dental Implant Planning. Dent Clin North Am, Vol (52), No.4, pp.761-75

Talwar N, Singh BP,Chand P.(2011).Use of Diagnostic and Surgical Stent: A Simplified Approach for Implant Placement. J Indian Prosthodont Soc, DOI 10.1007/s13191010-0036-7

Tardieu PB, Vrielinck L, Escolano E. (2003). Computer-assisted implant placement. A case report: treatment of the mandible. Int J Oral Maxillofac Implants, Vol (18), pp.599-604

Taylor TD, Agar JR, Voigiatzi (2000) Implant prosthodontics:current perspective and future directions. Int J Maxillofac Implants 15:66-75

Terakado M, Hashimoto K, Arai Y, Honda M, Sekiwa T, Sato H. (2000). Diagnostic imaging with newly developed ortho cubic super-high resolution computed tomography (Ortho-CT). Oral Surg Oral Med Oral Pathol Oral Radiol Endod, Vol (89), pp.509-518

Truhlar RS, Morris HF, Ochi S. (1993). A review of panoramic radiography and its potential use in implant dentistry. Implant Dent, Vol (2), No.2, pp. 122-30

Tyndall DA, Brooks SL. (2000). Selection criteria for dental site imaging: a position paper of the American Academy of oral and maxillofacial radiology. Oral surg oral med oral pathol oral radiol endod, Vol (89), pp.630-637

van Steenberghe D, Naert I, Andersson M, Brajnovic I, Van Cleynenbreugel J, Suetens P. (2002). A custom template and definitive prosthesis allowing immediate implant loading in the maxilla: a clinical report. Int J Oral Maxillofac Implants, Vol (17), pp.663-70

Van Steenberghe D, Malevez C, Van Cleynenbreugel J, Bou Serhal C, Dhoore E, Schutyser F, Suetens P, Jacobs R. (2003). Accuracy of drilling guides for transfer from threedimensional CT-based planning to placement of zygoma implants in human cadavers. Clin Oral Implants Res, Vol (14), No.1, pp.131-139

Vannier MW. (2003). Craniofacial computed tomography scanning:technology, applications and future trends. Orthod Craniofac Res, Vol (1), pp.23-30

Vercruyssen M, Quirynen M. (2010). Long-term, retrospective evaluation (implant and patient-centred outcome) of the two-implant-supported overdenture in the mandible. Part 2: marginal bone loss. Clin Oral Implants Res, Vol (2), No.5, pp.466-72

Vrielinck C, Politis S, Schepers M, Pauwels M, Naert I. (2003). Image-based planning and clinical validation of zygoma and pterygoid implant placement in patients with severe bone atrophy using customized drill guides. Preliminary results from a prospective clinical follow-up study. Int J Oral Maxillofac Surg, Vol (32),No.1, pp.7-14

Wismeijer D, van Waas MA, Vermeeren JI, Kalk W. (1997). Patients' perception of sensory disturbances of the mental nerve before and after implant surgery: a prospective study of 110 patients. Br J Oral Maxillofac Surg,Vol (35), No.4, pp.254-9

Woolson ST, Dev P, Fllingham LL, Vassiliadis A.(1986).Three-dimensional imaging of bone from computerized tomography. Clin Orthop Relat Res, Vol( 202), pp.239-248

Worthington P, Rubenstein J, Hatcher DC. (2010). The role of cone-beam computed tomography in the planning and placement of implants. J Am Dent Assoc, Vol (141), No.3, pp.19-24

Wouters K, Vrielinck L, Wivell C, Dhoore E. (2000). Further development of drilling templates for the placement of regular dental implants and zygomatic fixtures, based on preoperative planning on CT images. In: Lemke HU, Vannier MW, 
Inamura K, Farman A (eds). Computer-assisted radiology. Berlin:Elsevier Science,:945-949.

Yong LT, Moy PK. (2008). Complications of computer-aided-design/computer-aidedmachining-guided (NobelGuide) surgical implant placement: an evaluation of early clinical results.Clin Implant Dent Relat Res, Vol (10), No. 3, PP. Epub 123-7.

Zahran MH, Fenton A. (2010). A radiopaque implant template for partially edentulous patients. J Prosthet Dent, Vol (103), No.6, pp.390-2

Zinner ID, Panno FV, Small SA, Landa LS. (2004). Implant Dentistry: From Failure to Success. Quintessence Publishing 


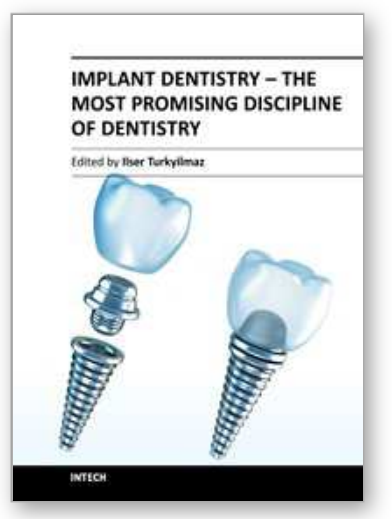

\author{
Implant Dentistry - The Most Promising Discipline of Dentistry \\ Edited by Prof. Ilser Turkyilmaz
}

ISBN 978-953-307-481-8

Hard cover, 476 pages

Publisher InTech

Published online 30, September, 2011

Published in print edition September, 2011

Since Dr. Branemark presented the osseointegration concept with dental implants, implant dentistry has changed and improved dramatically. The use of dental implants has skyrocketed in the past thirty years. As the benefits of therapy became apparent, implant treatment earned a widespread acceptance. The need for dental implants has resulted in a rapid expansion of the market worldwide. To date, general dentists and a variety of specialists offer implants as a solution to partial and complete edentulism. Implant dentistry continues to advance with the development of new surgical and prosthodontic techniques. The purpose of Implant Dentistry - The Most Promising Discipline of Dentistry is to present a comtemporary resource for dentists who want to replace missing teeth with dental implants. It is a text that integrates common threads among basic science, clinical experience and future concepts. This book consists of twenty-one chapters divided into four sections.

\title{
How to reference
}

In order to correctly reference this scholarly work, feel free to copy and paste the following:

Elnaz Moslehifard (2011). Computer Aided Techniques Developed for Diagnosis and Treatment Planning in Implantology, Implant Dentistry - The Most Promising Discipline of Dentistry, Prof. Ilser Turkyilmaz (Ed.), ISBN: 978-953-307-481-8, InTech, Available from: http://www.intechopen.com/books/implant-dentistry-the-mostpromising-discipline-of-dentistry/computer-aided-techniques-developed-for-diagnosis-and-treatment-planningin-implantology

\section{INTECH}

open science | open minds

\section{InTech Europe}

University Campus STeP Ri

Slavka Krautzeka 83/A

51000 Rijeka, Croatia

Phone: +385 (51) 770447

Fax: +385 (51) 686166

www.intechopen.com

\section{InTech China}

Unit 405, Office Block, Hotel Equatorial Shanghai

No.65, Yan An Road (West), Shanghai, 200040, China

中国上海市延安西路65号上海国际贵都大饭店办公楼 405 单元

Phone: +86-21-62489820

Fax: $+86-21-62489821$ 
(C) 2011 The Author(s). Licensee IntechOpen. This chapter is distributed under the terms of the Creative Commons Attribution-NonCommercialShareAlike-3.0 License, which permits use, distribution and reproduction for non-commercial purposes, provided the original is properly cited and derivative works building on this content are distributed under the same license. 